\title{
PKA modulation of Rac in neuronal cells
}

\author{
Akihiro Goto, Yuji Kamioka and Michiyuki Matsuda* \\ Department of Pathology and Biology of Diseases, Graduate School of Medicine, Kyoto University, Kyoto, Japan \\ ${ }^{*}$ Correspondence: matsuda.michiyuki.2c@kyoto-u.ac.jp
}

Edited by:

Pierre Vincent, Centre National de la Recherche Scientifique, France

Reviewed by:

Olivier C. G. Gavet, Institut Gustave Roussy, France

Jean-vianney Barnier, Centre National de la Recherche Scientifique, France

Keywords: PKA, Rac, guanine nucleotide exchange factor, migration

The Rho-family GTPase, Rac, is a molecular switch that controls actin dynamics and thereby the morphology, migration, and cytokinesis of most, if not all, cell types (Heasman and Ridley, 2008). Neuronal cells are not an exception, although Racregulated replication and migration are limited mostly to the embryonic stages (Luo, 2000; Tashiro and Yuste, 2004; Fuchs et al., 2009; Govek et al., 2011). Recently, it has also been shown that Rac is required for proliferative production and retention of new neurons generated during learning, indicating that Rac also regulates higher brain function (Haditsch et al., 2013). This small molecular switch is able to bring about so many different outcomes because it is embedded in many circuits, each of which comprises of a number of signaling molecules. Therefore, the function and regulation of Rac are inevitably cell context-dependent.

Protein kinase A (PKA), a canonical signal transducer of cAMP, plays pivotal roles in neuronal outgrowth, survival and regeneration (Qiu et al., 2002) and in axonal guidance (Song et al., 1998; Tojima et al., 2011). PKA activity is also required for the migration of enteric neural crestderived cells during development of the enteric nervous system (Barlow et al., 2003; Asai et al., 2006). These observations suggest that PKA may regulate Rac to induce $s$ a number of morphological changes. Here, we focus on the regulation of Rac by PKA in neuronal cells.

The direct upstream input to Rac comes from guanine nucleotide exchange factors (GEFs) and GTPase-activating proteins (Figure 1A). Among Ras-superfamily small GTPases, Rac, and Cdc42, a close relative of Racl, are unique in that they are activated by two structurally unrelated families of GEFs, the classical Dbl homology-pleckstrin homology domaincontaining GEFs (Cook et al., 2014) and the DOCK180-related atypical GEFs (Laurin and Cote, 2014). Among the more than 60 Dbl-family GEFs, Tiam1, STEF/Tiam2, P-Rex1, and Vav3 have been shown to regulate the migration of neuronal progenitor cells and neurite extension of neurons (Govek et al., 2011). On the other hand, studies with knockout mice or gene silencing of DOCK-family genes have revealed that DOCK3/MOCA deficiency leads to axonal degeneration and sensorimotor impairments (Chen et al., 2009), that DOCK6 is required for axon extension in dorsal root ganglion neurons (Miyamoto et al., 2013), and that DOCK7 regulates the interkinetic nuclear migration of radial glial progenitor cells (Yang et al., 2012).

At one level above GEF are various serine/threonine kinases, which phosphorylate GEFs and thereby activate or inactivate them. PKA is a good candidate for such a serine/threonine kinase; however, there have been no direct demonstrations of PKA regulation of GEFs for Rac, except for a few examples, in neuronal cells. In PC12D cells, PKA phosphorylates and activates a Rac GEF, STEF/Tiam2, and induces neurite extension (Goto et al., 2011). On the other hand, phosphorylation of P-Rex1, another GEF, has been shown to suppress GEF activity in HEK293T cells (Mayeenuddin and Garrison, 2006; Barber et al., 2012). Although knockout mice of P-Rex1 exhibit cerebellar dysfunction (Donald et al., 2008), it is unknown whether the PKA-P-Rexl axis operates in neuronal cells. Less is known about the direct link between PKA and DOCK-family GEFs. Only recently it has been shown that, in glioblastoma cells, PKA phosphorylates and stimulates DOCK180 and thereby promotes growth and invasion (Feng et al., 2014).

Additional complexity comes from the regulation by phosphoinositides and phosphatidic acid. Although the Dbl-family GEFs and the DOCK-family GEFs are structurally unrelated, both GEFs are regulated by phosphoinositides or phosphatidic acid, which are bound to the $\mathrm{PH}$ domain in the Dbl-family GEFs or the DHR-2 domain in the DOCK-family GEFs (Cook et al., 2014; Laurin and Cote, 2014). Considering the pleiotropic effects of PKA, it is likely that PKA regulates Rac by controlling the levels of phosphoinositides and phosphatidic acid. For example, PKA has been shown to activate phosphatidylinositol 3-kinase (PI3K) via p85 subunit phosphorylation (Cosentino et al., 2006). In another report, however, PKA was shown to inhibit PI3K via p110 subunit phosphorylation (Perino et al., 2011). Therefore, the effect of PKA on PI3K is cell contextdependent. The development of probes for phosphoinositides and phosphatidic acid will help to resolve this issue (Nishioka et al., 2010). Finally, PKA can directly inhibit Racl by phosphorylating at Ser 71 during bacterial infection (Brandt et al., 2009).

Furthermore, Bachmann et al. have reported a direct binding of Rac1 with PKA by GFP complementation assay (Bachmann et al., 2013). The PKA-Rac1 axis functions to activate ERK MAP kinase and thereby regulates cell proliferation. It should be studied further whether the 


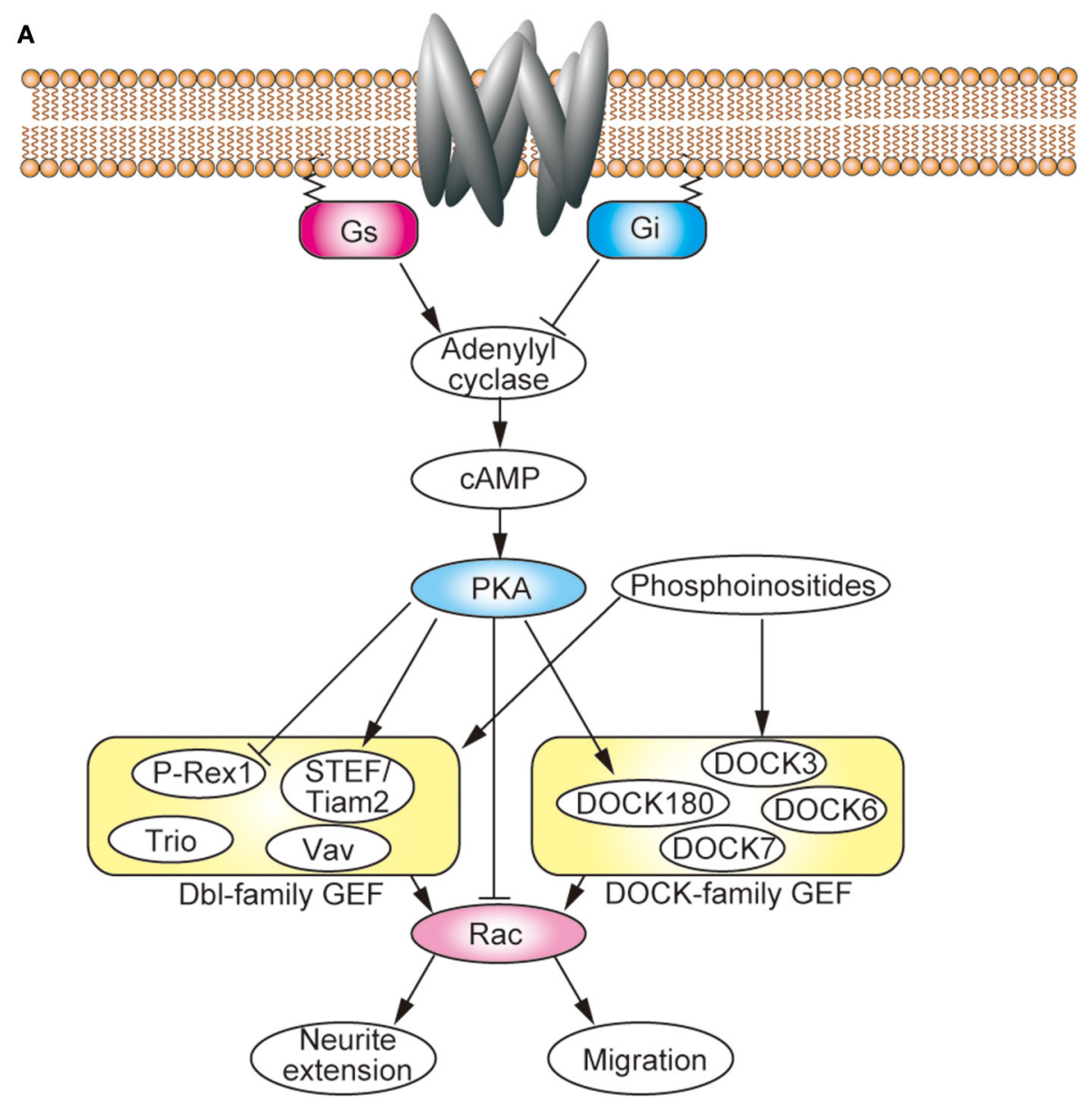

B Enteric Neural Crest-derived Cells

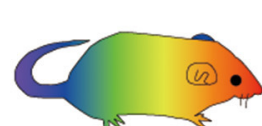

Transgenic mouse expressing a FRET biosensor

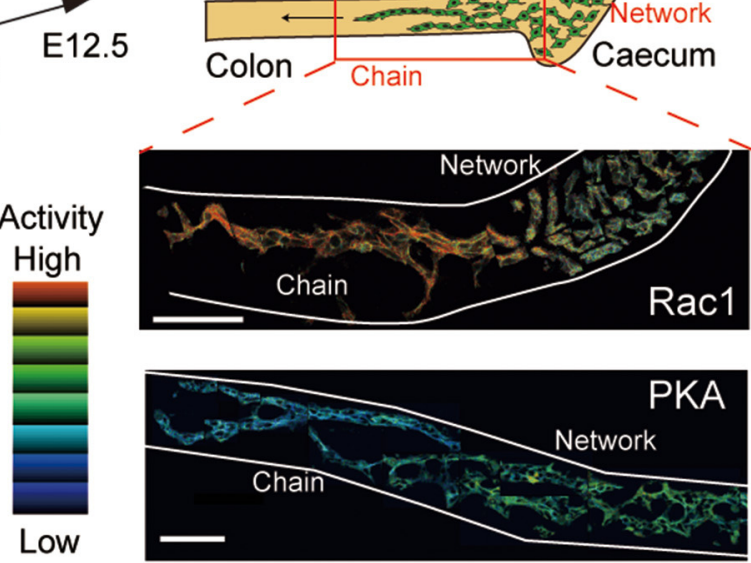

FIGURE 1 | Regulation of Rac by PKA in neuronal cells. (A) Schematic view of the regulatory network of Rac in neuronal cells. Neuronal cells express both Dbl-family and DOCK-family GEFs. Among them, P-Rex1, STEF/Tiam2, and DOCK180 have been shown to be phosphorylated by PKA. Rac activity is required for neurite extension, migration, and so on. (B) Transgenic mice expressing FRET biosensors can be used to examine the in vivo activities of Rac1 and PKA. Embryonic intestines of E12.5 derived from transgenic mice expressing a FRET biosensor for either Rac1 or PKA were observed under two-photon microscopes. FRET images were prepared to show the activity of Rac1 and PKA. Enteric neural crest cells (ENCCS) migrate from the stomach to the colon during development. The ENCCs that migrate rapidly in chains exhibit higher Rac1 activity and lower PKA activity than the ENCCs that form a neural network. 
PKA-Racl axis functions also in neuronal cells.

Due to the complexity and cell contextdependency of the regulatory networks where PKA and Rac are embedded, the role played by PKA in the regulation of $\mathrm{Rac}$ and the resulting morphological changes are almost entirely unpredictable in vivo. Thus, the activities of PKA and Rac should be examined together with biological outputs such as migration and neurite extension. To accomplish such comprehensive investigation, transgenic mice expressing biosensors based on the principle of Förster resonance energy transfer (FRET) were developed recently (Kamioka et al., 2012; Johnsson et al., 2014). By observing the embryonic intestines of transgenic mice expressing FRET biosensors for PKA and Rac1, clear reciprocal activation of PKA and Racl has been demonstrated in migrating enteric neural crest-derived cells (Figure 1B) (Goto et al., 2013). Currently, simultaneous observation of two FRET biosensors is a difficult task, but recent advent of bright infrared fluorescence will open a way to use two different FRET biosensors to visualize the interplay by two different signaling molecules in a single cell.

Further insight into the role played by PKA and Racl will be obtained by modulating the activity of Racl or PKA. Inhibitors against Racl and PKA are available; however, there is a critical problem for in vivo or ex vivo experiment. By the conventional bath application of reagents, we cannot tell whether the reagent affected the neuronal cells directly or indirectly via surrounding cells. Application of caged cAMP analogs or optogenetic tools such as light-activatable Racl (Wu et al., 2009) to the FRET biosensor-expressing mice will overcome this problem and help us to untangle the complex signaling networks that regulate the morphological changes of neuronal cells.

\section{ACKNOWLEDGMENTS}

Michiyuki Matsuda was supported by the Platform for Dynamic Approaches to Living System and by a Grant-in-Aid for Scientific Research on the Innovative Area "Fluorescence Live Imaging" (No. 22113002) from the Ministry of Education, Culture, Sports, Science, and
Technology (MEXT). The authors have no conflicting financial interests.

\section{REFERENCES}

Asai, N., Fukuda, T., Wu, Z., Enomoto, A., Pachnis, V., Takahashi, M., et al. (2006). Targeted mutation of serine 697 in the Ret tyrosine kinase causes migration defect of enteric neural crest cells. Development 133, 4507-4516. doi: 10.1242/dev.02616

Bachmann, V. A., Riml, A., Huber, R. G., Baillie, G. S., Liedl, K. R., Valovka, T., et al. (2013). Reciprocal regulation of PKA and Rac signaling. Proc. Natl. Acad. Sci. U.S.A. 110, 8531-8536. doi: 10.1073/pnas. 1215902110

Barber, M. A., Hendrickx, A., Beullens, M., Ceulemans, H., Oxley, D., Thelen, S., et al. (2012). The guanine-nucleotide-exchange factor P-Rex1 is activated by protein phosphatase lalpha. Biochem. J. 443, 173-183. doi: 10.1042/bj20112078

Barlow, A., de Graaff, E., and Pachnis, V. (2003). Enteric nervous system progenitors are coordinately controlled by the $\mathrm{G}$ protein-coupled receptor EDNRB and the receptor tyrosine kinase RET. Neuron 40, 905-916. doi: 10.1016/S08966273(03)00730-X

Brandt, S., Kenny, B., Rohde, M., Martinez-Quiles, N., and Backert, S. (2009). Dual infection system identifies a crucial role for PKA-mediated serine phosphorylation of the EPEC-Tir-injected effector protein in regulating Racl function. Cell. Microbiol. 11, 1254-1271. doi: 10.1111/j.14625822.2009.01330.x

Chen, Q., Peto, C. A., Shelton, G. D., Mizisin, A., Sawchenko, P. E., and Schubert, D. (2009). Loss of modifier of cell adhesion reveals a pathway leading to axonal degeneration. J. Neurosci. 29, 118-130. doi: 10.1523/jneurosci.3985-08.2009

Cook, D. R., Rossman, K. L., and Der, C. J. (2014). Rho guanine nucleotide exchange factors: regulators of Rho GTPase activity in development and disease. Oncogene 33, 4021-4035. doi: 10.1038/ onc.2013.362

Cosentino, C., Di Domenico, M., Porcellini, A., Cuozzo, C., De Gregorio, G., Santillo, M. R., et al. (2006). p85 regulatory subunit of PI3K mediates cAMP-PKA and estrogens biological effects on growth and survival. Oncogene 26, 2095-2103. doi: 10.1038/sj.onc. 1210027

Donald, S., Humby, T., Fyfe, I., Segonds-Pichon, A., Walker, S. A., Andrews, S. R., et al. (2008). P-Rex2 regulates Purkinje cell dendrite morphology and motor coordination. Proc. Natl. Acad. Sci. U.S.A. 105, 4483-4488. doi: 10.1073/pnas.0712324105

Feng, H., Hu, B., Vuori, K., Sarkaria, J. N., Furnari, F. B., Cavenee, W. K., et al. (2014). EGFRvIII stimulates glioma growth and invasion through PKA-dependent serine phosphorylation of Dock180. Oncogene 33, 2504-2512. doi: 10.1038/onc.2013.198

Fuchs, S., Herzog, D., Sumara, G., Buchmann-Moller, S., Civenni, G., Wu, X., et al. (2009). Stage-specific control of neural crest stem cell proliferation by the small rho GTPases Cdc42 and Rac1. Cell Stem Cell 4, 236-247. doi: 10.1016/j.stem.2009.01.017

Goto, A., Hoshino, M., Matsuda, M., and Nakamura, T. (2011). Phosphorylation of STEF/Tiam2 by protein kinase A is critical for Racl activation and neurite outgrowth in dibutyryl cAMP-treated PC12D cells. Mol. Biol. Cell 22, 1780-1790. doi: 10.1091/mbc.E10-09-0783

Goto, A., Sumiyama, K., Kamioka, Y., Nakasyo, E., Ito, K., Iwasaki, M., et al. (2013). GDNF and endothelin 3 regulate migration of enteric neural crest-derived cells via protein kinase A and Rac1. J. Neurosci. 33, 4901-4912. doi: 10.1523/JNEUROSCI.4828-12.2013

Govek, E. E., Hatten, M. E., and Van Aelst, L. (2011). The role of Rho GTPase proteins in CNS neuronal migration. Dev. Neurobiol. 71, 528-553. doi: 10.1002/dneu.20850

Haditsch, U., Anderson, M. P., Freewoman, J., Cord, B., Babu, H., Brakebusch, C., et al. (2013). Neuronal Racl is required for learning-evoked neurogenesis. J. Neurosci. 33, 12229-12241. doi: 10.1523/jneurosci.2939-12.2013

Heasman, S. J., and Ridley, A. J. (2008). Mammalian Rho GTPases: new insights into their functions from in vivo studies. Nat. Rev. Mol. Cell Biol. 9, 690-701. doi: 10.1038/nrm2476

Johnsson, A. K., Dai, Y., Nobis, M., Baker, M. J., McGhee, E. J., Walker, S., et al. (2014). The RacFRET mouse reveals tight spatiotemporal control of rac activity in primary cells and tissues. Cell Rep. 6, 1153-1164. doi: 10.1016/j.celrep.2014.02.024

Kamioka, Y., Sumiyama, K., Mizuno, R., Sakai, Y., Hirata, E., Kiyokawa, E., et al. (2012). Live imaging of protein kinase activities in transgenic mice expressing FRET biosensors. Cell Struct. Funct. 37, 65-73. doi: $10.1247 /$ csf. 11045

Laurin, M., and Cote, J. F. (2014). Insights into the biological functions of Dock family guanine nucleotide exchange factors. Genes Dev. 28, 533-547. doi: 10.1101/gad.236349.113

Luo, L. (2000). Rho GTPases in neuronal morphogenesis. Nat. Rev. Neurosci. 1, 173-180. doi: 10.1038/35044547

Mayeenuddin, L. H., and Garrison, J. C. (2006) Phosphorylation of P-Rexl by the cyclic AMP-dependent protein kinase inhibits the phosphatidylinositiol (3,4,5)-trisphosphate and Gbetagamma-mediated regulation of its activity. J. Biol. Chem. 281, 1921-1928. doi: 10.1074/jbc.M506035200

Miyamoto, Y., Torii, T., Yamamori, N., Ogata, T., Tanoue, A., and Yamauchi, J. (2013). Akt and PP2A reciprocally regulate the guanine nucleotide exchange factor Dock6 to control axon growth of sensory neurons. Sci. Signal. 6, ra15. doi: 10.1126/scisignal.2003661

Nishioka, T., Frohman, M. A., Matsuda, M., and Kiyokawa, E. (2010). Heterogeneity of phosphatidic acid levels and distribution at the plasma membrane in living cells as visualized by a Foerster resonance energy transfer (FRET) biosensor. J. Biol. Chem. 285, 35979-35987. doi: 10.1074/jbc.M110.153007

Perino, A., Ghigo, A., Ferrero, E., Morello, F., Santulli, G., Baillie, G. S., et al. (2011). Integrating cardiac PIP3 and cAMP signaling through a PKA anchoring function of p110gamma. Mol. Cell 42, 84-95. doi: 10.1016/j.molcel.2011.01.030

Qiu, J., Cai, D., Dai, H., McAtee, M., Hoffman, P. N., Bregman, B. S., et al. (2002). Spinal axon regeneration induced by elevation of cyclic AMP. Neuron 34, 895-903. doi: 10.1016/S0896-6273(02) 00730-4 
Song, H., Ming, G., He, Z., Lehmann, M., McKerracher, L., Tessier-Lavigne, M., et al. (1998). Conversion of neuronal growth cone responses from repulsion to attraction by cyclic nucleotides. Science 281, 1515-1518. doi: 10.1126/science.281.5382.1515

Tashiro, A., and Yuste, R. (2004). Regulation of dendritic spine motility and stability by Racl and Rho kinase: evidence for two forms of spine motility. Mol. Cell. Neurosci. 26, 429-440. doi: 10.1016/j.mcn.2004.04.001

Tojima, T., Hines, J. H., Henley, J. R., and Kamiguchi, H. (2011). Second messengers and membrane trafficking direct and organize growth cone steering. Nat. Rev. Neurosci. 12, 191-203. doi: $10.1038 / \mathrm{nrn} 2996$
Wu, Y. I., Frey, D., Lungu, O. I., Jaehrig, A., Schlichting, I., Kuhlman, B., et al. (2009). A genetically encoded photoactivatable Rac controls the motility of living cells. Nature 461, 104-108. doi: 10.1038/nature08241

Yang, Y. T., Wang, C. L., and Van Aelst, L. (2012). DOCK7 interacts with TACC3 to regulate interkinetic nuclear migration and cortical neurogenesis. Nat. Neurosci. 15, 1201-1210. doi: $10.1038 / \mathrm{nn} .3171$

Conflict of Interest Statement: The authors declare that the research was conducted in the absence of any commercial or financial relationships that could be construed as a potential conflict of interest.
Received: 30 June 2014; accepted: 24 September 2014; published online: 14 October 2014.

Citation: Goto A, Kamioka Y and Matsuda M (2014) PKA modulation of Rac in neuronal cells. Front. Cell. Neurosci. 8:321. doi: 10.3389/fncel.2014.00321

This article was submitted to the journal Frontiers in Cellular Neuroscience.

Copyright (C) 2014 Goto, Kamioka and Matsuda. This is an open-access article distributed under the terms of the Creative Commons Attribution License (CC BY). The use, distribution or reproduction in other forums is permitted, provided the original author(s) or licensor are credited and that the original publication in this journal is cited, in accordance with accepted academic practice. No use, distribution or reproduction is permitted which does not comply with these terms. 